Article

\title{
Study of Surfactant Additives for the Manufacture of Warm Mix Asphalt: From Laboratory Design to Asphalt Plant Manufacture
}

\author{
Miguel Sol-Sánchez, Fernando Moreno-Navarro and $\mathbf{M}^{\mathrm{a}}$ Carmen Rubio-Gámez * \\ Construction Engineering Laboratory of the University of Granada (LabIC.UGR), 18071 Granada, Spain; \\ msol@ugr.es (M.S.-S.); fmoreno@ugr.es (F.M.-N.) \\ * Correspondence: mcrubio@ugr.es; Tel.: +34-958-249-443; Fax: +34-958-246-138
}

Academic Editors: Zhanping You, Qingli (Barbara) Dai and Feipeng Xiao

Received: 20 June 2017; Accepted: 19 July 2017; Published: 21 July 2017

\begin{abstract}
Warm Mix Asphalt (WMA), manufactured at a lower temperature than the traditional Hot Mix Asphalt (HMA), allows for important economic and environmental benefits when considered for application in roads. Nonetheless, despite the benefits, its application in pavement for roads is not as widespread as desired from an environmental point of view; more in-depth studies to investigate its development and wider applicability are required. Thus, the present paper aims to contribute to the implementation of this cleaner technology to produce WMA (based on chemical additives) for its application in pavement for roads, including from the stage of the design of the material in the laboratory (by selecting the most appropriate manufacturing temperature and additive type and dosage) to its production in a conventional industrial plant for its use in a trial section. Results demonstrate that it is possible to reduce the manufacturing temperature of asphalt mixtures by using chemical additives, recording similar mechanical behaviour (or even superior) to conventional hot mixtures when specific studies are developed for the optimal design of the WMA. It was also shown that these mixtures could be produced in a conventional asphalt plant without implementing important changes in equipment, which implies a cost-effective solution that can readily be incorporated into traditional plant procedures.
\end{abstract}

Keywords: warm mix asphalt; additives; sustainability; water sensitivity; stiffness; plastic deformation

\section{Introduction}

Asphalt mixtures are the most widely used material in the construction of pavements for roads and highways around the world [1]. However, their use is associated with significant environmental pollution that is generated during manufacturing, placing and maintenance-namely the release of a large volume of greenhouse gases caused by the high manufacturing temperature (around $160{ }^{\circ} \mathrm{C}$ ). This also leads to high levels of energy consumption, and hence, construction costs [2,3]. Thus, in order to limit these problems [4], a cleaner production of bituminous mixtures is required to decrease the manufacturing temperature without reducing their mechanical behaviour.

One possible alternative is the use of Warm Mix Asphalt (WMA), which is manufactured at 20-40 ${ }^{\circ} \mathrm{C}$ lower than the conventional Hot Mix Asphalt (HMA) [5]. These mixtures were developed to significantly reduce harmful emissions and energy consumption without compromising the mechanical performance of the material [6-8]. In particular, a number of studies [9-11] have demonstrated that the use of WMA in pavements for roads allows for lower emissions, fumes and odors; a reduction of ageing of the bitumen; a decrease in fuel consumption in plant; a more rapid turnover of traffic; and an increase in haulage distances among other economic and environmental advantages, due to the 
reduction in manufacturing and paving temperature. As a result of these potential benefits, WMA has attracted a considerable amount of attention in the USA as well as in various European countries in recent years [1,9].

The reduction in WMA temperature is the consequence of recent technologies that can be divided into different categories depending on the agent used, and includes organic additives, chemical additives, and foaming (water-based or water-containing) [5]. Despite this qualification, all of these technologies share the same objective - an improvement in mixture workability and aggregate coating at lower temperatures by reducing bitumen viscosity or modifying its surface tension for better aggregate wetting [12]. Among these technologies, the use of chemical additives (which are liquid surfactants that act at the microscopic aggregate/binder interface to reduce internal friction during manufacturing) is one of the most common solutions, since these additives require minimal changes to the manufacturing process. Further, they act as anti-stripping agents that increase the adhesion between aggregates and bitumen, thereby reducing problems associated with WMA such as stripping and raveling [13]. Moreover, in contrast to other techniques such as the use of foam bitumen, their use does not require special investment or modifications in the manufacturing plant. As a result, new WMA surfactant additives that require further investigation have been emerging, and the choice of these materials is often a subjective decision based on the skill of the engineer. Therefore, in-depth studies are required to provide useful knowledge about the suitability of these additives for application in pavement construction as well as their capacity to improve the mechanical performance of asphalt mixtures manufactured at low temperatures [3]. Moreover, most of the work on WMA with chemical additives has focused on laboratory analysis, with relatively few studies conducted in a real life field setting [14-17]. The latter type of study is essential to demonstrate the effectiveness of reproducing these WMAs in real asphalt plants for their application in pavements for roads.

Given this lack of knowledge and its potential to reduce environmental issues associated with asphalt mixtures, the current paper set out to examine the effectiveness of various additives in improving the behaviour of WMA at a range of manufacturing temperatures $\left(145^{\circ} \mathrm{C}\right.$ and $\left.120^{\circ} \mathrm{C}\right)$. To do this, the performance of each WMA was compared with that of conventional hot mix asphalt (manufactured at $165^{\circ} \mathrm{C}$ ) without additives, which was used as a control. Further, the present study evaluates the impact of the dosage of the additive in order to define the optimal design of WMA for its use in pavement for roads. Finally, a study of the reproducibility of the laboratory-designed WMA in a real plant was conducted, along with its application in a trial section, evaluating its mechanical performance in comparison with conventional HMA.

\section{Methodology}

\section{Materials}

For this study, the same type of asphalt mixture was used as that used in the production of both the HMA (used as a reference) and the various WMAs with different chemical additives (applied during manufacturing in order to reduce the temperature of mixing). Such a mixture has a dense-graded mix type AC 22 35/50 S (EN 13108-1) whose mineral skeleton is composed of limestone aggregates (which allows for sufficient contact with the bitumen to achieve a bond between binder and aggregates) [18] for the different fractions $(0 / 6,6 / 12,12 / 18$, and $18 / 25 \mathrm{~mm})$ with a maximum particle size equal to $22 \mathrm{~mm}$. The main properties of these aggregates are displayed in Table 1, where it is clear that this material presents appropriate characteristics for its application in the manufacturing of asphalt mixtures. 
Table 1. Aggregates properties.

\begin{tabular}{|c|c|c|c|c|c|}
\hline \multicolumn{2}{|c|}{ Properties } & \multirow{2}{*}{$\begin{array}{c}18 / 25 \\
\% \text { passing }\end{array}$} & \multirow{2}{*}{$\begin{array}{c}\mathbf{1 2 / 1 8} \\
\% \text { passing }\end{array}$} & \multirow{2}{*}{$\begin{array}{c}\mathbf{6 / 1 2} \\
\% \text { passing }\end{array}$} & \multirow{2}{*}{$\begin{array}{c}\mathbf{0 / 6} \\
\% \text { passing }\end{array}$} \\
\hline \multirow{9}{*}{ Particle size (UNE-EN 933-1) } & Sieves $(\mathrm{mm})$ & & & & \\
\hline & 25 & 100 & 100 & 100 & 100 \\
\hline & 22 & 90 & 100 & 100 & 100 \\
\hline & 16 & 4 & 38 & 100 & 100 \\
\hline & 8 & 0 & 0 & 23 & 100 \\
\hline & 2 & 0 & 0 & 0 & 62 \\
\hline & 0.5 & 0 & 0 & 0 & 28 \\
\hline & 0.25 & 0 & 0 & 0 & 16 \\
\hline & 0.063 & 0.1 & 0.2 & 0.1 & 3.0 \\
\hline \multicolumn{2}{|c|}{ Coarse aggregate shape. Flakiness index (UNE-EN 933-3) } & 5.25 & 5.82 & 12.01 & - \\
\hline \multicolumn{2}{|c|}{ Percentage of fractured face (UNE-EN 933-5) } & 95.8 & 95.2 & 97.1 & - \\
\hline \multirow{2}{*}{\multicolumn{2}{|c|}{$\begin{array}{l}\text { Resistance to fragmentation (UNE-EN 1097-2) } \\
\text { Cleaning (organic impurity content) (UNE-EN 146130) }\end{array}$}} & 24.7 & 24.7 & 24.7 & - \\
\hline & & 0.26 & 0.99 & 2.27 & - \\
\hline \multicolumn{2}{|c|}{ Sand equivalent (UNE-EN 933-8) } & - & - & - & 83.02 \\
\hline \multirow{4}{*}{$\begin{array}{l}\text { Relative density and absorption } \\
\text { (UNE-EN 1097-6) }\end{array}$} & Apparent density $\left(\mathrm{Mg} / \mathrm{m}^{3}\right)$ & 2.73 & 2.75 & 2.71 & 2.80 \\
\hline & $\operatorname{ADSS}\left(\mathrm{Mg} / \mathrm{m}^{3}\right)$ & 2.68 & 2.69 & 2.64 & 2.72 \\
\hline & Density after drying $\left(\mathrm{Mg} / \mathrm{m}^{3}\right)$ & 2.70 & 2.71 & 2.66 & 2.75 \\
\hline & Water absorption (\%) & 0.64 & 0.81 & 0.93 & 1.03 \\
\hline
\end{tabular}

Filler was recovered from the crushing of limestone rocks, which provides fine particles with alkaline properties that facilitate the adhesion with bitumen. This material was less than $0.063 \mathrm{~mm}$ in size for more than $96 \%$ of the particles, with a density equal to $0.6 \mathrm{Mg} / \mathrm{m}^{3}$ (EN 1097-3). The binder employed was type B35/50 whose penetration was equal to $44 \mathrm{dmm}$ (EN 1426) with a softening point of approximately $52{ }^{\circ} \mathrm{C}$ (EN 1427).

With all of these materials, the asphalt mixture was manufactured using a bitumen dosage equal to $4 \%$ over the total mass. The mixture used as a reference to evaluate the influence of the different additives was manufactured at $165^{\circ} \mathrm{C}$, which is a common temperature for this type of mixture. Table 2 lists the main physical and mechanical properties for this material, where it is possible to see that the mixture presents appropriate properties for its application in asphalt pavements for roads.

Table 2. Main properties of the asphalt mixture.

\begin{tabular}{ccc}
\hline Property & Standard & HMA \\
\hline Apparent density $\left(\mathrm{g} / \mathrm{cm}^{3}\right)$ & EN 12697-6 & 2.477 \\
Mix air void content $(\%)$ & EN 12697-8 & 4.1 \\
Aggregates air void $(\%)$ & EN 12697-8 & 13.7 \\
Marshall stability $(\mathrm{kN})$ & EN 12697-34 & 17.79 \\
Marshall deformation $(\mathrm{mm})$ & EN 12697-34 & 4.1 \\
\hline
\end{tabular}

In order to be able to decrease the manufacturing temperature for the WMA, three types of surfactant additives were used, which are referred to in this study as A1 (a traditional surfactant additive with amine composition), A2 (a nano-additive that modifies the alkalinity of the aggregate surface) and A3 (a vegetable additive with active surface properties). Before the manufacturing of the various WMA, the additives were blended with the bitumen by using a rotational blender at 300 revolutions per minute for $10 \mathrm{~min}$. The temperature of blending was around $160{ }^{\circ} \mathrm{C}$, and after this process the bitumen was incorporated directly into the mixer over the aggregates at various temperatures $\left(145^{\circ} \mathrm{C}\right.$ or $120^{\circ} \mathrm{C}$, depending on the case studied). The mixing time was similar to that used for the HMA, and the compaction temperature was almost $10^{\circ} \mathrm{C}$ lower than the mixing temperature (as was the case for the conventional hot mix asphalt). 


\section{Testing Plan and Methods}

By using the conventional AC $22 \mathrm{~S}$ mixture (manufactured at around $165^{\circ} \mathrm{C}$ ) as a reference, the testing plan developed in this study included three different steps (Table 3) in order to design and apply an asphalt mixture at a lower temperature with appropriate mechanical performance: (i) analysis of the effect of various additives to reduce the manufacturing temperature (evaluating its effectiveness under different manufacturing temperatures); (ii) optimisation of the mixture design (definition of the most appropriate manufacturing temperature and additive dosage) by using the additive selected in the previous stage; and (iii) reproducibility of the WMA in a real asphalt plant, and study of its mechanical behaviour in the laboratory. In addition, the effect of different manufacturing temperatures $\left(145^{\circ} \mathrm{C}\right.$ and $\left.120^{\circ} \mathrm{C}\right)$ was analysed in the first two steps, while in the third step an optimal temperature was chosen on the basis of the results obtained in the previous steps.

Table 3. Testing plan.

\begin{tabular}{|c|c|c|c|c|c|}
\hline \multirow{2}{*}{ Study Step } & \multirow{2}{*}{ Asphalt Mix } & \multicolumn{2}{|c|}{ Additive } & \multirow{2}{*}{ Temperature ${ }^{\circ} \mathrm{C}$} & \multirow{2}{*}{ Tests } \\
\hline & & Type & $\%$ & & \\
\hline \multirow{7}{*}{$\begin{array}{c}\text { Effect of different } \\
\text { additives on WMA } \\
\text { behaviour }\end{array}$} & HMA165 & - & - & 165 & \multirow{7}{*}{$\begin{array}{l}\text { Workability } \\
\text { I. tensile strength } \\
\text { Water sensitivity } \\
\text { Stiffness Triaxial }\end{array}$} \\
\hline & WMA-1-0.5-145 & A1 & & & \\
\hline & WMA-2-0.5-145 & $\mathrm{A} 2$ & 0.5 & 145 & \\
\hline & WMA-3-0.5-145 & A3 & & & \\
\hline & WMA-1-0.5-120 & A1 & \multirow{3}{*}{0.5} & \multirow{3}{*}{120} & \\
\hline & WMA-2-0.5-120 & $\mathrm{A} 2$ & & & \\
\hline & WMA-3-0.5-120 & A3 & & & \\
\hline \multirow{5}{*}{$\begin{array}{l}\text { Optimisation of } \\
\text { WMA design }\end{array}$} & HMA165 & - & - & 165 & \multirow{5}{*}{$\begin{array}{l}\text { Workability } \\
\text { I. tensile strength } \\
\text { Water sensitivity } \\
\text { Stiffness Triaxial }\end{array}$} \\
\hline & WMA-S-0.5-145 & \multirow{4}{*}{ Selected } & 0.5 & 145 & \\
\hline & WMA-S-0.05-145 & & 0.05 & 145 & \\
\hline & WMA-S-0.5-120 & & 0.5 & 120 & \\
\hline & WMA-S-0.05-120 & & 0.05 & 120 & \\
\hline \multirow{2}{*}{$\begin{array}{l}\text { Production of WMA } \\
\text { in asphalt plant }\end{array}$} & HMA165 & - & - & 165 & \multirow{2}{*}{$\begin{array}{c}\text { Density } \\
\text { Water sensitivity } \\
\text { Stiffness Triaxial }\end{array}$} \\
\hline & WMA-S-S-S & Selected & Selected & Selected & \\
\hline
\end{tabular}

In the first step, the behaviour of 7 asphalt mixes was analysed: the conventional mix used as a reference and manufactured at $165^{\circ} \mathrm{C}$ without additives (known as HMA165); and six mixes manufactured at $145^{\circ} \mathrm{C}$ and $120^{\circ} \mathrm{C}$, including the three different chemical agents with a dosage of $0.5 \%$ over the mass of the bitumen (known as WMA-X-Y-Z, where $\mathrm{X}$ refers to type of additive, $\mathrm{Y}$ to the dosage, and $\mathrm{Z}$ to the manufacturing temperature). This percentage was selected since it is the usual value employed when using chemical additives in the production of WMA [19,20], whilst this quantity was maintained at a constant value for the three additives in order to compare their effect on the mix behaviour. Moreover, the temperature values were selected according to the range commonly used for WMA, which allows for determining the effect of this parameter by using both extreme values of temperatures used in the production of WMA.

To analyse the effect of the different additives on the behaviour of the WMA, the workability and compactibility of the various mixes was studied using a gyratory compactor. In addition, for the different specimens (4 for each mix) obtained from the workability study, its indirect tensile strength was evaluated to analyse the influence of each additive on the coating of the mix at low temperatures. The stiffness modulus test [21], water sensitivity test [22], and triaxial test [23] were also conducted for the different mixes in order to evaluate the impact of the additives on the behaviour of the mixes under the main mechanical properties (bearing capacity, water susceptibility, and resistance to plastic deformations) for their application in pavements for roads. 
The second step of the testing plan consisted of studying the effect of the dosage of additive used (for the additive selected as the most appropriate in the previous step) while evaluating the impact of manufacturing temperature. This step was carried out with the aim of both optimising the design of the WMA, and obtaining a mechanical performance that is comparable with the conventional HMA. To do so, the behaviour of the asphalt mix was examined when manufactured at $145^{\circ} \mathrm{C}$ and $120^{\circ} \mathrm{C}$ by using $0.5 \%$ of additive (quantity employed in the previous step) and $0.05 \%$. The percentage was considerably reduced in order to clearly identify the effect of the quantity of this component on the behaviour of the mixture, analysing whether this reduction in additive plays an essential role. Further, the choice of dosage was guided by the manufacturer's suggestion for finding the optimal solution to reduce production costs associated with using the chemical agent. On the other hand, in addition to the WMA mixtures, the performance of a conventional HMA was evaluated for use as a reference for analysing the influence of the additive. The properties evaluated were the workability and compactibility of the different solutions (which included determining the tensile strength), stiffness modulus [21], water sensitivity [22], and triaxial test [23].

The third study step involved the production of the laboratory-designed WMA in a conventional asphalt plant, in accord with the results obtained in the previous stages. In addition, a trial section was paved with both the WMA and the conventional HMA (used as a control) in order to study the long-term behaviour of these mixtures in further studies. During the spreading process, samples of both types of asphalt mix were collected in order to study their behaviour in laboratory, and to then assess the viability of manufacturing this kind of material in conventional asphalt plants. The tests developed to evaluate the response of both mixtures were density [24], stiffness modulus [21], water sensitivity [22], and triaxial test [23].

The workability test was developed by using a gyratory compactor that allows for observing the relationship between the energy transmitted to the specimen and the level of compaction obtained, by analysing the aptitude of the material to be compacted at low temperatures. The total number of cycles applied was 210 gyros, in order to evaluate the evolution of the density of the material. In addition, after manufacturing 4 specimens for each mix, the indirect tensile strength was measured at $20^{\circ}$ by using the method developed in [25].

The water sensitivity test [22] involves the manufacture of cylindrical specimens that are compacted with 35 blows on each side by a Marshall hammer in order to reproduce low compaction energy, thereby simulating more unfavorable conditions against water action. The specimens were divided into two sets of three specimens: a dry set and a wet set. The set of dry specimens was stored at room temperature in the laboratory $\left(15 \pm 5^{\circ} \mathrm{C}\right)$, whereas a vacuum process was applied to the wet set for $30 \pm 5 \mathrm{~min}$ until a pressure of $6.7 \pm 0.3 \mathrm{kPa}$ was obtained. The wet specimens were then immersed in water at a temperature of $40^{\circ} \mathrm{C}$ for a period of $72 \mathrm{~h}$. The next step was to carry out an indirect traction resistance test [25] on each of the cylinders (in both the dry set and the wet set) at a temperature of $15^{\circ} \mathrm{C}$, and to compare their indirect tensile strength through the ITSR (Indirect Tensile Strength Ratio, which is obtained by dividing the strength of the wet set by the strength of the dry set in terms of percentage).

The stiffness modulus was measured according to [21], which consists of manufacturing cylindrical specimens compacted with 75 blows on each side. After conditioning the specimens at $20^{\circ} \mathrm{C}$ for at least $2 \mathrm{~h}$, they were placed and secured in a vertical position of one of its diameters, applying 10 load pulses to adjust the magnitude of the load and its duration. In order to measure the deformation of the diameter, 5 additional load pulses were applied to measure and record the load variation and deformation in the time period of each pulse. At the same time, the surface load factor was also determined. As a final result, the stiffness modulus was obtained for two diameters of the specimen (forming an angle of $90 \pm 10^{\circ}$ ).

The triaxial test [23] entails the combination of a confining load of $120 \mathrm{kPa}$ and another cyclic sinusoidal out-of-phase axial loading of $300 \mathrm{kPa}$ at a frequency of $3 \mathrm{~Hz}$ for 12,000 load cycles. The creep and permanent deformation parameters for each specimen (cylinders with a diameter of $101.6 \mathrm{~mm}$ 
and a sawn-off height of $60 \mathrm{~mm}$ ) are calculated, and the results obtained in the test are shown as the mean of the values obtained for three test specimens. During the current study, the triaxial test was carried out at $60{ }^{\circ} \mathrm{C}$ in order to assess the resistance of the material to plastic deformation under severe climate conditions.

\section{Results}

\section{Effect of Different Additives on WMA Behaviour}

Figure 1 shows the curves of densification (reduction in air void content) of the asphalt mixtures manufactured at $145^{\circ} \mathrm{C}$ (Figure 1a) and $120^{\circ} \mathrm{C}$ (Figure $1 \mathrm{~b}$ ) with $0.5 \%$ of various additives, as well as the curve measured for the conventional HMA. From the results, it is clear that the use of additives during the manufacturing of mixtures at $145^{\circ} \mathrm{C}$ allows for workability that is comparable to that obtained for the conventional HMA, since quite similar air void content (near 4.5-5.5\%) was recorded, highlighting the case of the additive A2. In addition, the workability study showed that the use of these chemical additives to reduce the manufacturing temperature to around $20^{\circ} \mathrm{C}$ allows for values of density higher than $98 \%$, in reference to the conventional HMA $\left(2.44 \mathrm{Mg} / \mathrm{m}^{3}\right)$, which indicates its suitability for application in pavements for roads, avoiding the problems often associated with the low level of compaction for this material [26].

For the mixtures manufactured at a lower temperature (around $120^{\circ} \mathrm{C}$ ), the results revealed that in this case the effectiveness of the additives is slightly lower than in the previous case (manufactured at $145^{\circ} \mathrm{C}$ ), since higher values of air void content were recorded, indicating lower compaction of the asphalt mixture associated with lower workability due to the increase in bitumen viscosity when the temperature is reduced. Nonetheless, the additives A1 and A2 led to decrease in densification in reference to that presented by the HMA, which allows for density values close to $98 \%$, which was measured for the conventional hot mix asphalt. This shows that the use of these two additives could be appropriate for manufacturing WMA at $120^{\circ} \mathrm{C}$ whilst adequate workability and compaction characteristics are obtained in reference to traditional HMA, which is in accord with other studies examining the use of additives for WMA $[27,28]$. Therefore, these results suggest that the use of these two additives reduces susceptibility to manufacturing temperature with respect to the additive $\mathrm{A} 3$, which led to a significant decrease in density when the temperature was reduced from $145^{\circ} \mathrm{C}$ to $120^{\circ} \mathrm{C}$.
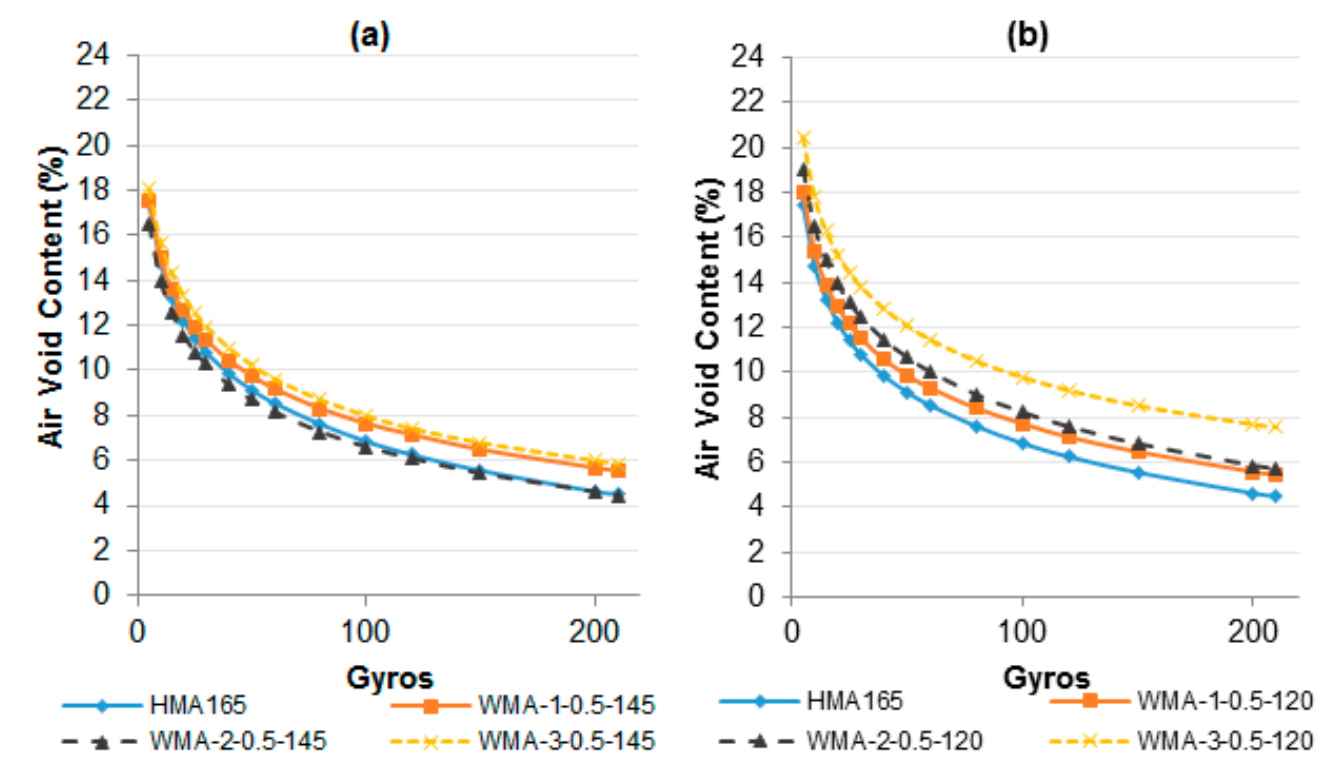

Figure 1. Densification curves of the mixtures with various additives and different manufacturing temperatures. (a) $145^{\circ} \mathrm{C}$ vs. $165^{\circ} \mathrm{C}$; (b) $120^{\circ} \mathrm{C}$ vs. $165^{\circ} \mathrm{C}$. 
In order to obtain a more in-depth study of the influence of the different additives, Figure 2 displays the values of Indirect Tensile Strength (ITS measured in $\mathrm{kPa}$ ) measured for the specimens from the workability study (with gyratory compactor) for the different mixtures at low temperatures with the additives A1, A2 and A3, as well as the results obtained for the HMA. In addition, the Indirect Tensile Strength Ratio (ITSR) values obtained in the water sensitivity test [22] are shown in order to evaluate the moisture susceptibility of the various mixtures analysed.

According to the results, it appears that the use of the different additives to manufacture WMA at $145{ }^{\circ} \mathrm{C}$ leads to quite similar values of ITS to those measured for the HMA, thereby avoiding the failure of the mixture associated with the reduction in adhesion and cohesion due to the decrease in manufacturing temperature, which could in turn lead to coating problems. Similarly, application of the additives generally improved the ITSR values, which reflects an important reduction in water sensitivity for the WMA manufactured at $145^{\circ} \mathrm{C}$ when using the additives analysed. These findings are also in agreement with other studies that employed chemical additives to act as anti-stripping agents $[29,30]$. However, when the reduction in manufacturing temperature is higher (near $45^{\circ} \mathrm{C}$ ), it is important to note that a significant decrease in tensile strength could occur, despite the fact that the ITSR are quite similar to those presented by the HMA (with the exception of the additive A3, which showed an important increase in water sensitivity for the mixture manufactured at $120^{\circ} \mathrm{C}$ ), and therefore, the durability of the material could also be reduced.

With respect to the effectiveness of each of the chemical additives, the present results show that A1 and A2 lead to quite similar WMA performance, obtaining even higher tensile strength (in the case of A2) and lower water sensitivity than the HMA. In reference to the additive A3, this appeared to be less effective in avoiding the reduction in tensile strength and resistance to water due to the decrease in manufacturing temperature, which is probably a consequence of the lower capacity of this chemical additive to improve the adhesiveness between bitumen-aggregates by reducing the surface tension and increasing the wetting of aggregates [13].

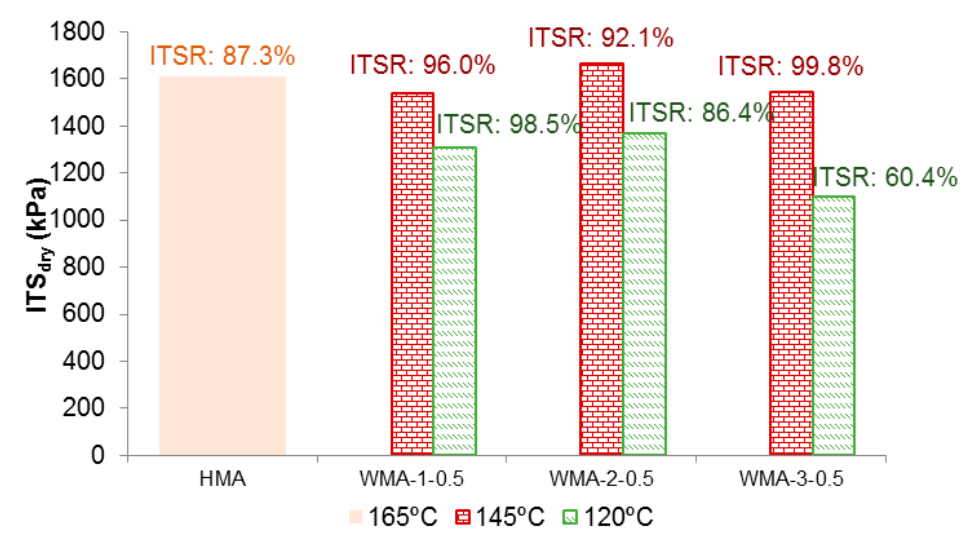

Figure 2. Indirect Tensile Strength (ITS) and Indirect Tensile Strength Ratio (ITSR) results for the mixtures with various additives.

Figure 3 shows the influence of the different additives on the stiffness modulus (at $20^{\circ} \mathrm{C}$ ) of the asphalt mixture manufactured at low temperatures. The results show that, in general, the WMA presented lower stiffness modulus than the HMA, regardless of the type of additive. In addition, it is clear that the lower the manufacturing temperature, the lower the stiffness modulus. Whilst this could be associated with lower compaction of the specimens (particularly in the case of the mixtures manufactured at $120^{\circ} \mathrm{C}$ ), the decrease in modulus could also be due to lower ageing of the bitumen during the manufacturing process, since the temperature is reduced by $20-45^{\circ} \mathrm{C}$ in reference to the case of the HMA, and therefore, the short-term stiffening of the bitumen is lower $[14,19]$. Thus, the mixtures manufactured at $120^{\circ} \mathrm{C}$ showed higher reduction in stiffness modulus, obtaining quite similar values for the different additives, while in the case of the mixtures manufactured at $145^{\circ} \mathrm{C}$, the additive $\mathrm{A} 2$ 
led to a slight increase in bearing capacity, which could also be influenced by higher density values, according to the results described previously.

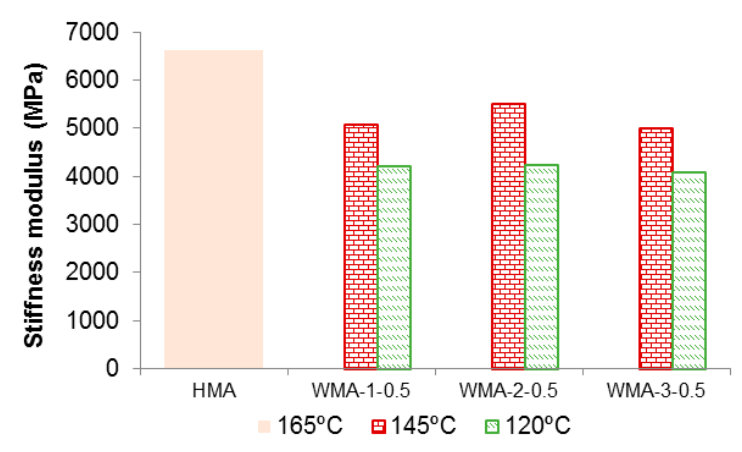

Figure 3. Stiffness modulus at $20^{\circ} \mathrm{C}$ for the mixtures with different additives.

As the decrease in stiffness modulus in the WMA could be due to lower stiffening of the bitumen, lower resistance to rutting could be also obtained [14]. Figure 4 displays the resistance to permanent deformation for each mixture in order to show the effectiveness of these chemical additives in reducing the stiffening of the asphalt mixture whilst avoiding higher rutting deformations. In particular, Figure 4 presents the results obtained on the triaxial test, showing the final permanent deformation and the ratio of creep during the last loading cycles. The results indicate that the reduction in manufacturing temperature to $120^{\circ} \mathrm{C}$ led to an important increase in plastic deformations, which could be associated with a decreased stiffness of the bitumen along with the lack of compaction. This effect was more marked for additives A1 and A3.

However, in the case of the mixtures manufactured at $145^{\circ} \mathrm{C}$, the decrease in binder stiffening due to the reduction in temperature was balanced with density values close to those shown by the conventional HMA (Figure 1), obtaining fewer permanent deformations, even in the case of additives $\mathrm{A} 2$ and $\mathrm{A} 3$. This indicates the ability of these chemical additives to reduce the manufacturing temperature of asphalt mixtures, which decreases stiffening whilst allowing the WMA to maintain a bearing capacity and resistance to permanent deformations that is comparable to conventional HMA.

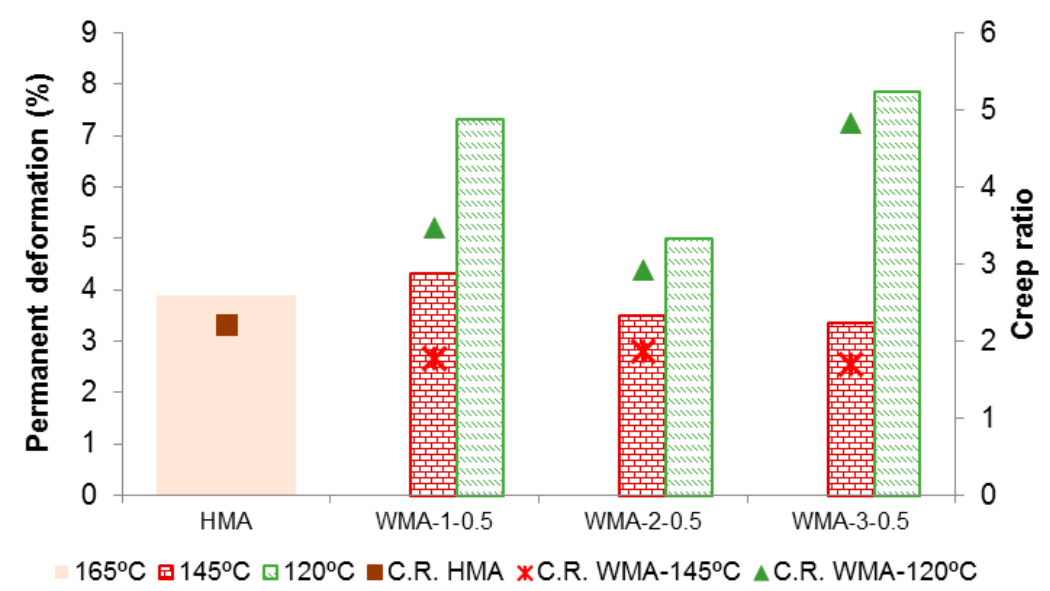

Figure 4. Triaxial results for the Hot Mix Asphalt (HMA) and Warm Mix Asphalt (WMA) with different additives.

\section{Optimization of the WMA Design}

Based on the previous results, the A2 additive appears be appropriate for use in manufacturing low energy asphalt mixtures, since it shows mechanical performance that is comparable to conventional 
HMA, obtaining higher tensile strength, water resistance, bearing capacity, and resistance to plastic deformations than the case of the WMA used with other additives. The additive A2 was therefore selected as the most appropriate for studying the optimization of the WMA design, with a view to its later use in a real asphalt plant. Figure 5 compares the workability of WMA with $0.5 \%$ of additive (the quantity commonly used) and $0.05 \%$ (the quantity defined to assess the possibility of reducing the amount of additive used), taking the conventional HMA as a reference.

The results show that for both manufacturing temperatures $\left(145^{\circ} \mathrm{C}\right.$ and $120^{\circ} \mathrm{C}$, in Figure $5 \mathrm{a}, \mathrm{b}$, respectively), the quantity of additive exerts little influence, since both dosages generated rather similar curves of the evolution of the air void content in the asphalt mixtures. Regarding the effect of temperature, it appears that it is possible to obtain similar values of air void content to those measured for the HMA at the manufacturing temperature of $145^{\circ} \mathrm{C}$, which indicates the ability of this additive to improve the workability of the material despite the decrease in temperature. Moreover, despite the reduction in additive effectiveness at lower temperatures (around $120^{\circ} \mathrm{C}$ ), the air void content for such mixtures was lower than around $6 \%$, obtaining density values higher than $98 \%$ over the conventional HMA. Thus, these results indicate that the use of this additive allows for appropriate workability and compaction of the asphalt mixture at low temperatures (within $120-145^{\circ} \mathrm{C}$ ), presenting little effect of the dosage of additive utilized (between $0.05 \%$ and $0.5 \%$ in this study).
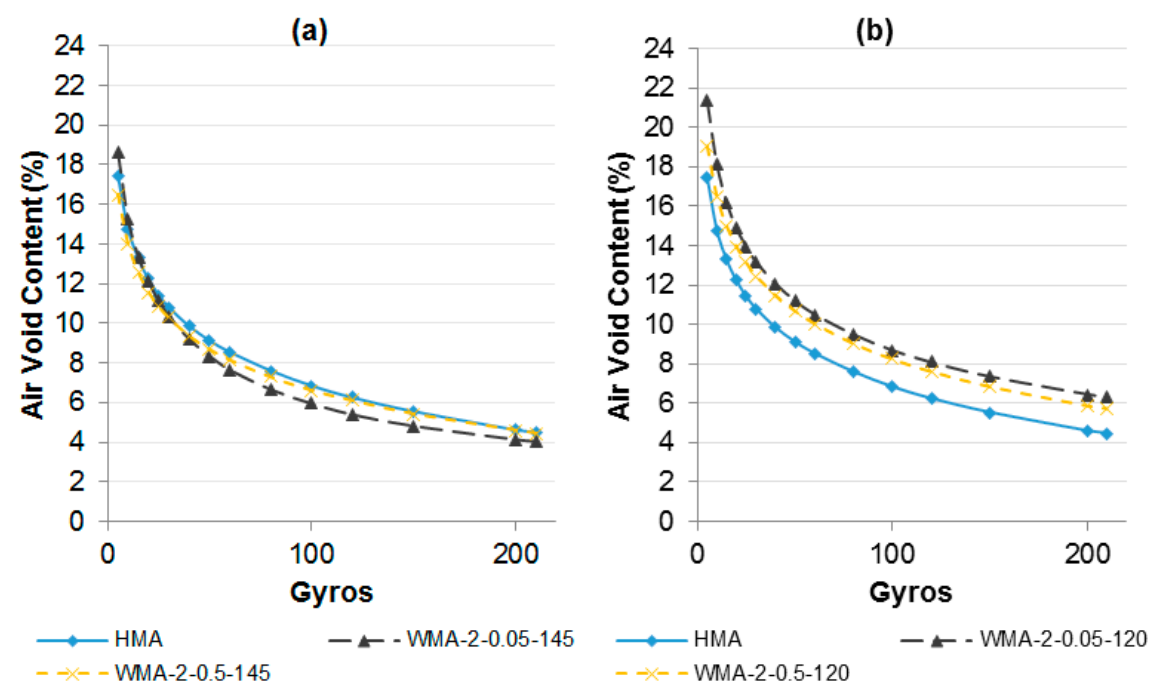

Figure 5. Densification curves for the HMA and WMA with different quantities of additives and manufacturing temperatures. (a) $145^{\circ} \mathrm{C}$ vs. $165^{\circ} \mathrm{C}$; (b) $120^{\circ} \mathrm{C}$ vs. $165^{\circ} \mathrm{C}$.

In addition, Figure 6 shows that although the decrease in additive dosage could lead to a slight increase in water sensitivity of the mixture, using a low quantity of this chemical agent (around $0.05 \%$ over the bitumen mass) allows for comparable (or even higher) indirect tensile strength to both the conventional HMA and the WMA with a higher amount of additive $(0.5 \%)$. This fact indicates that despite the lower value of ITSR that is measured in WMA [14], the values of tensile strength under wet conditions make it acceptable for application when compared with the mixtures used as a reference in this study.

In addition, the decrease in additive dosage was shown to be more effective in reducing the effect of manufacturing temperature (within $120-145^{\circ} \mathrm{C}$ ) on the behaviour of the asphalt mixture under tensile effort and water action, since quite similar values of ITS and ITSR were recorded for both temperatures when $0.05 \%$ of additive was used. In contrast, applying a higher amount of additive $(0.5 \%)$ led to a decrease in tensile strength of the asphalt mixture when the manufacturing temperature was reduced to $120^{\circ} \mathrm{C}$. This fact could be associated with the nano-composition of this additive (A2), 
which acts at the microscopic aggregate/bitumen interface [13], thereby improving performance when low quantities are used since it is possible to avoid the formation of agglomerations [14].

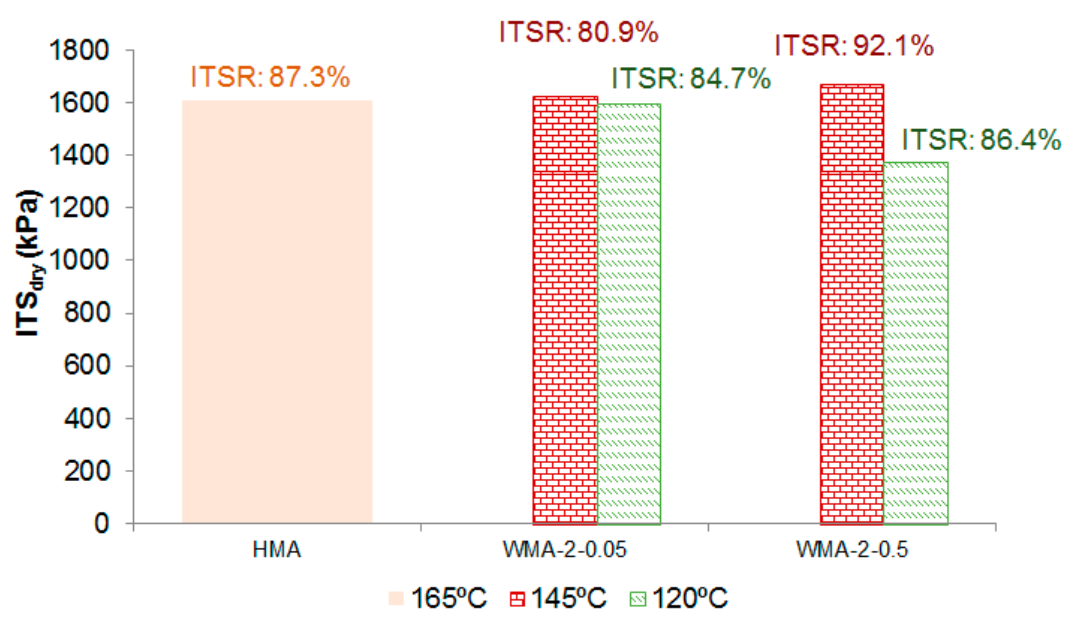

Figure 6. ITS (Indirect Tensile Strength) and water sensitivity results for the HMA and WMA with different quantities of additive under various manufacturing temperatures.

Similarly, Figure 7 shows that reducing the quantity of additive seems to be more effective in yielding a higher stiffness modulus (compared with using $0.5 \%$ additive) under the same manufacturing temperatures (producing a similar reduction in bitumen ageing). This is particularly important for a temperature of $120^{\circ} \mathrm{C}$, where a significant increase in bearing capacity was recorded when the dosage of additive was reduced. This could be related to a lower modification of the bitumen properties when the additive percentage is reduced, and thus a lower reduction in stiffness modulus is presented despite the fact that in both cases $(0.5 \%$ and $0.05 \%$ additive) similar density values were recorded.

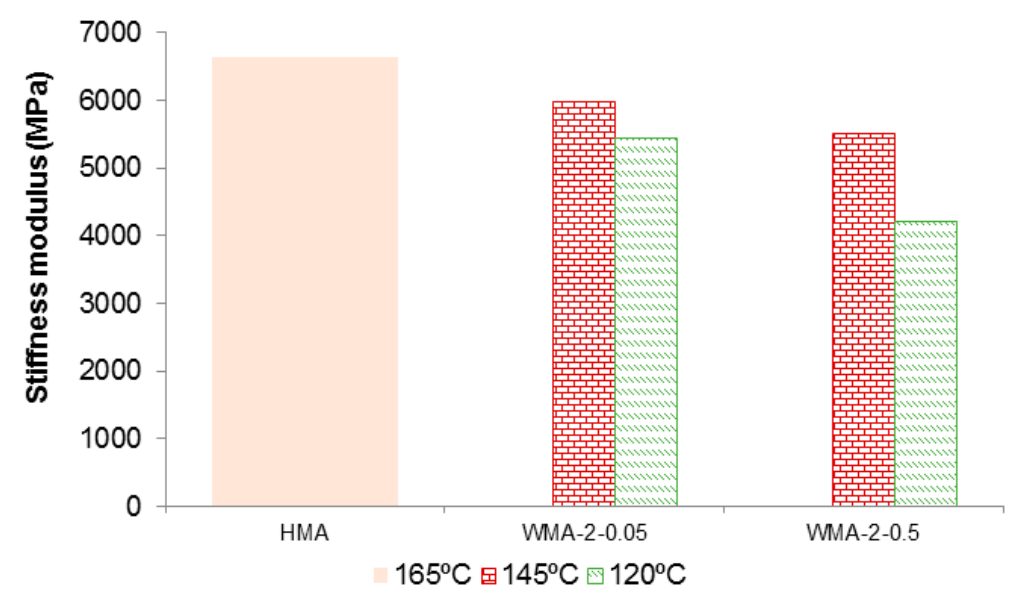

Figure 7. Effect of the quantity of additive and manufacturing temperature on the stiffness modulus of WMA.

Figure 8 displays the results obtained on the triaxial test for the WMA with different quantities of A2 as well as for the conventional HMA, used as a reference. Based on these results, it appears that the use of $0.05 \%$ of this additive improves resistance to plastic deformations of the asphalt mixture compared with the HMA (which could be due to improved workability and compaction when the additive is used), showing a similar performance at both of the low temperatures $\left(120-145^{\circ} \mathrm{C}\right)$. However, it should be noted that the increase in additive content could lead to the behaviour of the 
mixture being more susceptible to the manufacturing temperature, since in the case of using $0.5 \%$ additive, the mixture manufactured at $120{ }^{\circ} \mathrm{C}$ presented an increase in plastic deformations (both final deformation and ratio of creep), which could lead to the appearance of rutting deformation during its application in pavements for roads in comparison with the other WMA solutions and the conventional HMA.

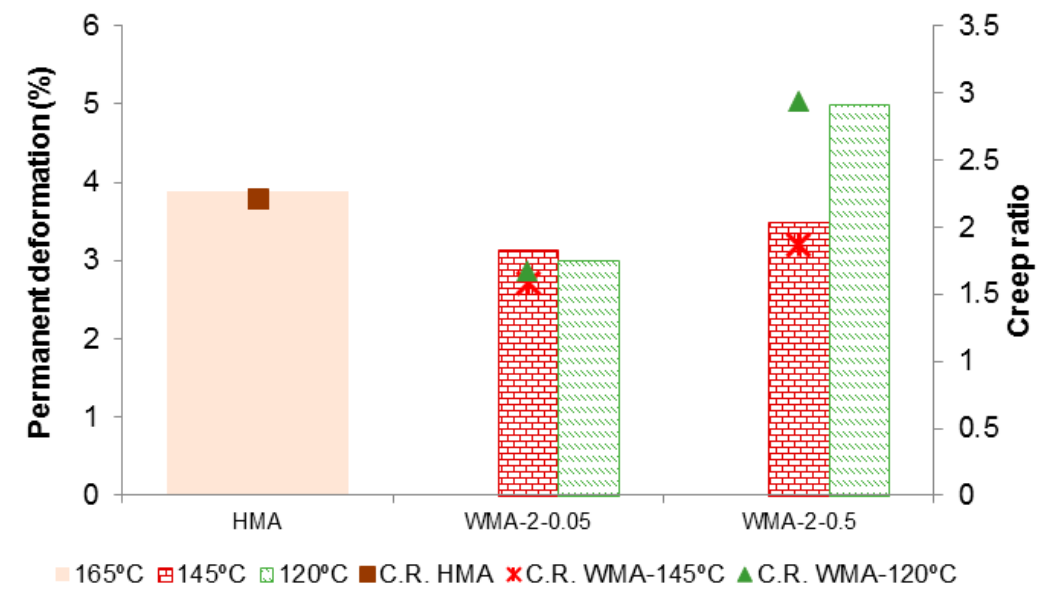

Figure 8. Effect of additive quantity and manufacturing temperature on the resistance to plastic deformations of WMA.

\section{Production of WMA in Plant, and Evaluation in Laboratory}

In accord with the previous findings, it was observed that the use of $0.05 \%$ additive (A2) could lead to appropriate mechanical performance of asphalt mixtures (with adequate workability, bearing capacity, and higher resistance to water action and to permanent deformations than the other dosage analysed) in comparison with HMA. In addition, it appears that the manufacturing temperature (ranging between $120-145^{\circ} \mathrm{C}$ ) has a relatively lower impact on WMA performance. Therefore, in order to analyse the performance of WMA in the field, an asphalt mixture manufactured at $130{ }^{\circ} \mathrm{C}$ including $0.05 \%$ of Additive type 2 was produced in a conventional discontinuous plant in order to study its reproducibility without the need to modify plant equipment, evaluating its mechanical performance in reference to HMA manufactured in the same plant at around $165^{\circ} \mathrm{C}$.

As shown in Figure 9A, firstly the additive was mixed directly with the hot bitumen (around $160{ }^{\circ} \mathrm{C}$ ) for $20 \mathrm{~min}$ using a blender in order to obtain a homogenous mix of additive and bitumen. After this, the modified bitumen was mixed with warm aggregates (at $130{ }^{\circ} \mathrm{C}$ as shown in Figure 9B), applying a similar mixing time to that used for HMA before starting the spreading and compaction process.

To determine the abilities of WMA manufactured in a conventional discontinuous plant, Table 4 shows the mechanical performance of both WMA and HMA during the spreading process (Figure 9C,D). The results indicate that despite a slight reduction in density of the WMA, both asphalt mixtures showed comparable density and air void content, implying the workability and compactibility of WMA. In addition, these values were quite similar to those measured for the mixtures manufactured in laboratory, which indicates good reproducibility of the WMA in a real asphalt plant.

Regarding the mechanical response of the mixtures, Table 4 shows that the WMA presented an even higher indirect tensile strength ratio under the water action while the tensile strength was quite similar to that measured for the conventional HMA. This could be associated with appropriate coating of aggregates in the WMA despite the decrease in manufacturing temperature, obtaining a good cohesiveness of the mixture as a result of using the chemical additive. Nonetheless, it is important to note that a slight reduction in stiffness and resistance to plastic deformations was recorded for the WMA in reference to the conventional HMA. This effect could be due to lower ageing of the bitumen 
during the manufacturing process, and therefore less stiffening of the asphalt mixture was observed, which is in accord with other studies [14,19].
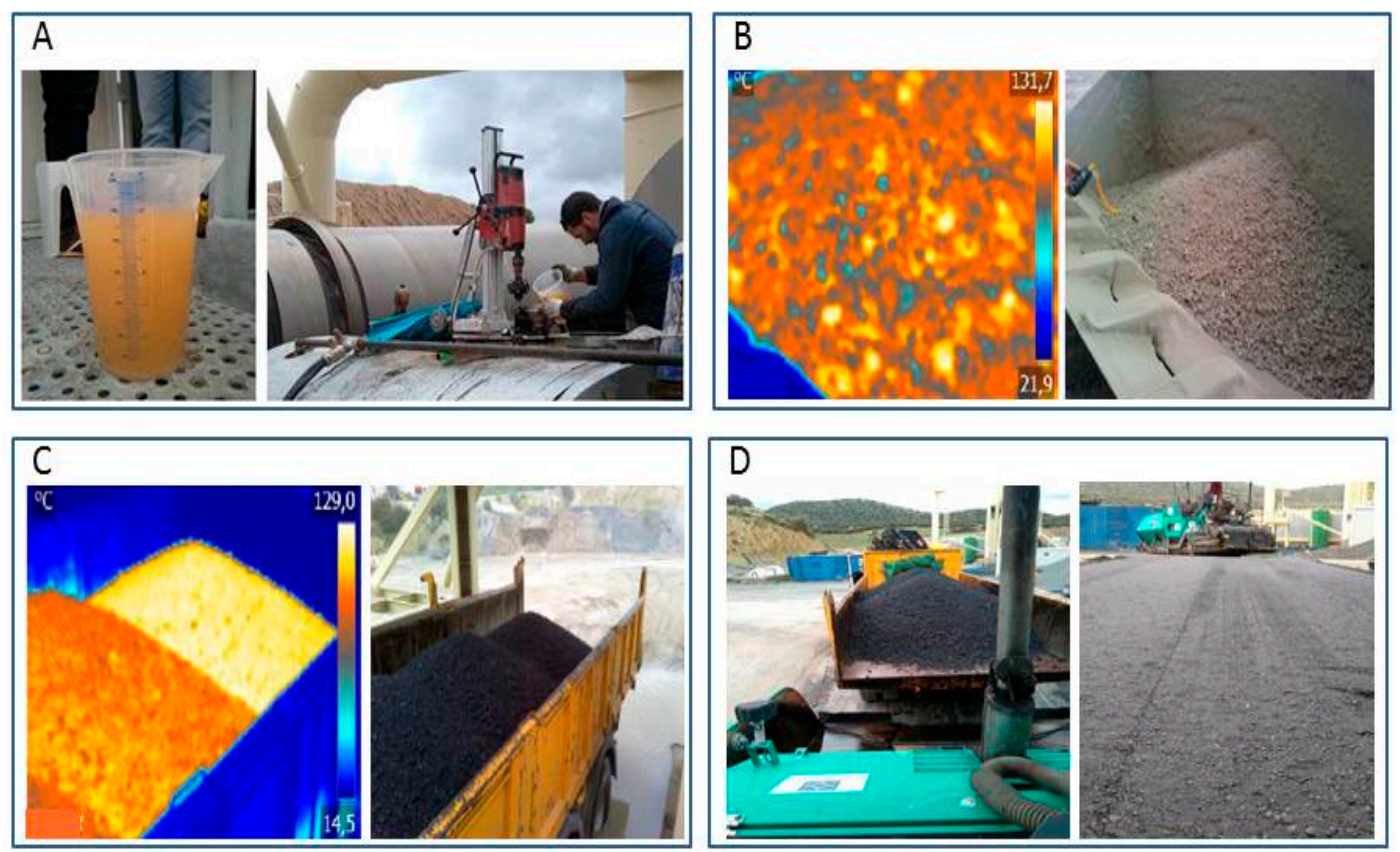

Figure 9. Visual appearance of the process for manufacturing the WMA with the chemical additive. (A) incorporation of additive to bitumen; (B) aggregates temperature; (C) WMA temperature; (D) spreading and compaction of the WMA.

Table 4. Results recorded for the HMA and WMA manufactured in a real asphalt plant.

\begin{tabular}{|c|c|c|c|c|c|c|c|}
\hline \multirow{2}{*}{ Mix } & \multirow{2}{*}{$\begin{array}{l}\text { Density } \\
\left(\mathrm{Mg} / \mathrm{m}^{3}\right)\end{array}$} & \multirow{2}{*}{$\begin{array}{c}\text { Air Void } \\
\text { Content }(\%)\end{array}$} & \multicolumn{2}{|c|}{ Water Susceptibility } & \multirow{2}{*}{$\begin{array}{l}\text { Stiffness Modulus } \\
\text { at } 20{ }^{\circ} \mathrm{C}(\mathrm{MPa})\end{array}$} & \multicolumn{2}{|c|}{ Triaxial } \\
\hline & & & ITS Dry (kPa) & ITSR (\%) & & P. def. (\%) & Creep Ratio \\
\hline WMA & 2.451 & 5.7 & 1530.2 & 96.0 & 6626.3 & 2.76 & 1.1 \\
\hline HMA & 2.471 & 5.0 & 1569.6 & 91.4 & 7371.2 & 1.71 & 0.7 \\
\hline
\end{tabular}

\section{Conclusions}

The present paper aims to analyse the effectiveness of various chemical additives used to manufacture asphalt mixtures at lower temperatures, to determine whether a cleaner technology can be employed for the production of asphalt mixtures with appropriate mechanical behaviour for application in pavements for roads. To this end, this study focused on determining the optimal design parameters of a WMA by examining its use in a real asphalt plant and applying the mixture in a trial section, as well as assessing its mechanical properties through the use of laboratory tests. On the basis of the results obtained in this study, the following conclusions can be drawn:

1. The manufacturing and compaction temperature has a strong impact on the behaviour of the mixture, obtaining better results when the manufacturing temperature is around $145^{\circ} \mathrm{C}$. Nonetheless, the behaviour of mixtures with the A1 and A2 additives appeared to be less susceptible to the effects of temperature than the material produced with $\mathrm{A} 3$ additives.

2. For mixtures manufactured at $145^{\circ} \mathrm{C}$, the results showed that the use of certain additives even allowed for an improvement in mixture workability, tensile strength, and water susceptibility in comparison with conventional HMA.

3. The results reveal that the use of certain chemical additives in WMA leads to lower stiffness modulus, without reducing the resistance to plastic deformations in reference to HMA. This 
indicates the possibility of obtaining more flexible mixtures without reducing strength, which could result in greater longevity of the mixtures. Nonetheless, there is a need for more in-depth studies on this topic.

4. The $\mathrm{A} 2$ additive was identified as the most appropriate in this study on the basis of the laboratory results, and it was shown that using a lower dosage $(0.05 \%$ over the bitumen mass, instead of $0.5 \%$ that is commonly used with chemical additives) allowed for lower susceptibility to the manufacturing temperature, whilst better mechanical performance was recorded. This fact could be associated with the nano-composition of this additive, which acts at the microscopic aggregate/bitumen interface.

5. This study indicates that WMA can be produced in a conventional discontinuous plant without incorporating any significant changes to the equipment and manufacturing process.

6. Moreover, the WMA presented appropriate density and air void values when compared to the HMA, whilst comparable tensile strength and water sensitivity was also recorded. Nonetheless, in this case, the reduction in stiffness modulus of the WMA produced a decrease in resistance to plastic deformations, which should be considered in further studies focusing on its application in bituminous pavements.

Taken together, the results obtained in this study suggest that, at least when using tensoactive additives, it is possible to manufacture cleaner asphalt mixtures at lower temperatures (WMA), with the material showing comparable mechanical behaviours to that recorded for conventional hot mixtures. In addition, it was also shown that this type of mixture could be manufactured in a conventional asphalt plant without the need to modify the equipment.

Acknowledgments: The authors wish to offer a special acknowledgement to the company Construcciones Pérez Jiménez SA, whose involvement in the study has made possible the manufacture and evaluation of the materials in a real plant and trial section scale.

Author Contributions: Miguel Sol-Sánchez has collaborated in carrying out the experimental plan and writing the paper; Fernando Moreno-Navarro has taken part in the experimental plan and writing the paper; $\mathrm{M}^{\mathrm{a}}$ Carmen Rubio Gámez has supervised the experimental plan while revising and correcting the paper.

Conflicts of Interest: The authors declare no conflict of interest.

\section{References}

1. Asphalt in Figures. Available online: www.eapa.org (accessed on 21 July 2017).

2. Kristjansdottir, O. Warm Mix Asphalt for Cold Weather Paving. Ph.D. Thesis, University of Washington, Seattle, WA, USA, 2006.

3. Almeida-Costa, A.; Benta, A. Economic and environmental impact study of warm mix asphalt compared to hot mix asphalt. J. Clean. Prod. 2016, 112, 2308-2317.

4. Moretti, L.; Mandrone, V.; D'Andrea, A.; Caro, S. Comparative from cradle to gate life cycle assessments of Hot Mix Asphalt (HMA) materials. Sustainablility 2017, 9, 400. [CrossRef]

5. Rubio, M.C.; Martínez, G.; Baena, L.; Moreno, F. Warm mix asphalt: An over-view. J. Clean. Prod. 2012, 24, 76-84. [CrossRef]

6. Capitão, S.D.; Picado-Santos, L.G.; Martinho, F. Pavement engineering materials: Review on the use of warm-mix asphalt. Constr. Build. Mater. 2012, 36, 1016-1024. [CrossRef]

7. Behl, A.; Kumar, G.; Sharma, G.; Jain, P.K. Evaluation of field performance of warm-mix asphalt pavements in India. Procedia Soc. Behav. Sci. 2013, 104, 158-167. [CrossRef]

8. Blankendaal, T.; Schuur, P.; Voordjik, H. Reducing the environmental impact of concrete and asphalt: A scenario approach. J. Clean. Prod. 2014, 66, 27-36. [CrossRef]

9. D'Angelo, J.; Harm, E.; Bartoszek, J.; Baumgardner, G.; Corrigan, M.; Cowsert, J.; Harman, T.; Jamshidi, M.; Jones, W.; Newcomb, D.; et al. Warm-Mix Asphalt: European Practice; Report No. FHWA-PL-08-007; International Technology Scanning Program: Washington, DC, USA, 2008. 
10. Pérez-Martínez, M.; Moreno-Navarro, F.; Martín-Marín, J.; Ríos-Losada, C.; Ruubio-Gámez, M.C. Analysis of cleaner technologies based on waxes and surfactant additives in road construction. J. Clean. Prod. 2014, 65, 374-379. [CrossRef]

11. Dinis-Almeida, M.; Afonso, M.L. Warm mix recycled asphalt-A sustainable solution. J. Clean. Prod. 2015, 107, 310-316. [CrossRef]

12. Jamshidi, A.; Golchin, B.; Hamzah, M.O.; Turner, P. Selection of type of warm mix asphalt additive based on the rheological properties of asphalt binders. J. Clean. Prod. 2015, 100, 89-106. [CrossRef]

13. Banerjee, A.; Smit, A.F.; Prozzi, J.A. The effect of long-term aging on the reology of warm mix asphalt binders. Fuel 2012, 97, 603-611. [CrossRef]

14. Bower, N.; Wen, H.; Willoughby, K.; Weston, J.; DeVol, J. Evaluation of the performance of warm mix asphalt in Washington state. WSDOT Res. Rep. 2012, 789, 1. [CrossRef]

15. Wen, H.; Wu, S. Performance of WMA technologies: Stage II Long-term field performance. Research Project NCHRP 09-49. In Proceedings of the Asphalt Mixture ETG Meeting, Fall Rivers, MA, USA, 7-8 April 2015.

16. Gu, F.; Luo, X.; Zhang, Y.; Lytton, R.L. Using overlay test to evaluate fracture properties of field-aged asphalt concrete. Constr. Build. Mater. 2015, 101, 1059-1068. [CrossRef]

17. Sol-Sánchez, M.; Moreno-Navarro, F.; García-Travé, G.; Rubio-Gámez, M.C. Analysing the industrial manufacturing in-plant and in-service performance of asphalt mixtures cleaner technologies. J. Clean. Prod. 2016, 121, 56-63. [CrossRef]

18. Zhang, J.; Apeagyei, A.; Airey, G.D.; Grenfell, J.R.A. Influence of aggregate mineralogical composition on water resistance of aggregate-bitumen adhesion. Int. J. Adhes. Adhes. 2015, 62, 45-54. [CrossRef]

19. Hurley, G.; Prowell, B. Evaluation of Evotherm for Use in Warm Mix; National Center for Asphalt Technology: Auburn, AL, USA, 2006.

20. Kuang, Y. Evaluation of Evotherm as a WMA Technology Compaction and Anti-Strip Additive. Bachelor's Thesis, Iowa State University, Ames, IA, USA, 2012.

21. EN 12697-26. Bituminous Mixtures-Test Methods for Hot Mix Asphalt_Parte 26: Stiffness; AENOR (Asociación Española de Normalización y Certificación): Madrid, Spain, 2012.

22. EN 12697-12. Bituminous Mixtures_Test Methods for Hot Mix Asphalt_Parte 12: Determination of the Water Sensitivity of Bituminous Specimens; AENOR (Asociación Española de Normalización y Certificación): Madrid, Spain, 2009.

23. EN 12697-25. Bituminous Mixtures-Test Methods for Hot Mix Asphalt-Parte 25: Cyclic Compression Test; AENOR (Asociación Española de Normalización y Certificación): Madrid, Spain, 2006.

24. EN 12697-6. Bituminous Mixtures_Test Methods for Hot Mix Asphalt_Parte 6: Determination of Bulk Density of Bituminois Specimens; AENOR (Asociación Española de Normalización y Certificación): Madrid, Spain, 2012.

25. EN 12697-23. Bituminous Mixtures-Test Methods for Hot Mix Asphalt_Parte 23: Determination of the Indirect Tensile Strength of Bituminous Specimens; AENOR (Asociación Española de Normalización y Certificación): Madrid, Spain, 2004.

26. Brown, E.R. Density of asphalt concrete-How much is needed? In Proceedings of the 69th Annual Meeting of the Transportation Research Board, Washington, DC, USA, 8-9 January 1990.

27. Mogawer, W.S.; Austerman, A.J.; Engstrom, B.; Bonaquist, R. Incorporating High Percentages of Recycled Asphalt Pavement (RAP) and Warm Mix Asphalt (WMA) Technology into Thin Hot Mix Asphalt Overlays to be Utilized as a Pavement Preservation Strategy. In Proceedings of the Transportation Research Board, Washington, DC, USA, 11-15 January 2009.

28. Tao, M.; Mallick, R.B. Effects of Warm Mix Asphalt additives on workability and mechanical properties of reclaimed asphalt pavement material. J. Transp. Res. Board 2009, 2126, 151-160. [CrossRef]

29. Ahmed, T.A.H. Investigating the Rutting and Moisture Sensitivity of Warm Mix Asphalt with Varying Contents of Recycled Asphalt Pavement. Bachelor's Thesis, University of IOWA, Iowa City, IA, USA, 2014.

30. Buss, A.; Christopher, R.; Schram, S. Evaluation of moisture susceptibility tests for war mix asphalt. Constr. Build. Mater. 2016, 102, 358-366. [CrossRef]

(C) 2017 by the authors. Licensee MDPI, Basel, Switzerland. This article is an open access article distributed under the terms and conditions of the Creative Commons Attribution (CC BY) license (http:/ / creativecommons.org/licenses/by/4.0/). 